\title{
Ascitic calprotectin as a useful marker in the diagnosis of spontaneous bacterial peritonitis in adults
}

\author{
Eman M Abdel Rahman ${ }^{1}$, Fatma A Attia', Ayman Alsebaey ${ }^{2^{*}}$ (D), Mohammad Abdel Khalik Elkady ${ }^{3}$, \\ Maha Mohammed Sayed ${ }^{4}$, Alaa Reda Awad $^{5}$ and Eman Ahmed El-Seidi ${ }^{5}$
}

\begin{abstract}
Background: Ascitic fluid polymorphonuclear leucocyte count (PMN) is known to be the gold standard for spontaneous bacterial peritonitis (SBP) diagnosis. The aim of this work was to assess ascitic calprotectin for SBP diagnosis. Serum C-reactive protein (CRP), high sensitivity C-reactive protein (hsCRP), nitrous oxide, ascitic PMN, ascitic leucocyte esterase and ascitic calprotectin were measured.

Results: The average age of our patients was $55.25 \pm 7.89$ years, mostly males $(n=51,63.8 \%)$, anti-HCV antibodies were positive in $(n=61,76.3 \%)$. Sixty-four patients (80\%) were Child-Pugh C and their average MELD was $24.29 \pm 8.06$. Patients with SBP had statistically significant higher median MELD score (26.5 vs. 19) and higher average Child-Pugh score (12.18 \pm 1.74 vs. $10.5 \pm 1.97)$. Forty patients had SBP and 40 patients were without SBP. Both the serum and ascitic nitrous oxide did not differ statistically between patients with and without SBP. In contrast, patients with SBP had higher median serum CRP (49 vs. $12 \mathrm{mg} / \mathrm{dL}$ ), hsCRP (58,000 vs. 23,750 ng/dL) and ascitic calprotectin (7.57 vs. 1.1 $\mathrm{ng} / \mathrm{mL}$ ). The ascitic leucocyte esterase test was positive in 95\% of SBP patients in contrast to $2.5 \%$ patients without SBP. Ascitic calprotectin $>2 \mathrm{ng} / \mathrm{mL}$ had $90 \%$ sensitivity, $92.5 \%$ specificity, $92.3 \%$ positive predictive value and $90.2 \%$ negative predictive value. MELD, CRP, hSCRP and ascitic calprotectin are independent predictors of SBP.
\end{abstract}

Conclusion: Ascitic calprotectin is a useful marker for SBP diagnosis.

Keywords: Ascites, Calprotectin, hsCRP, Spontaneous bacterial peritonitis

\section{Background}

Spontaneous bacterial peritonitis (SBP) is an infection of the ascitic fluid in patients with liver cirrhosis and portal hypertension [1]. There is no obvious surgical cause as perforation or intraabdominal inflammatory focus as abscess. Up to $30 \%$ of the ascitic patients will develop SBP [2].

SBP is attributed to immune dysfunction, bacterial translocation, circulatory dysfunction and inflammatory status. SBP is diagnosed by ascitic fluid analysis [3]. SBP was defined as polymorphonuclear leucocyte count $(\mathrm{PMN})>250 / \mathrm{mm}^{3}$ in ascitic fluid [2, 4]. Not all cases are associated with positive ascitic fluid cultures.

\footnotetext{
* Correspondence: aymanalsebaey@liver.menofia.edu.eg

${ }^{2}$ Department of Hepatology and Gastroenterology, National Liver Institute,

Menoufia University, Shebeen El-Kom 32511, Egypt

Full list of author information is available at the end of the article
}

There are variants of ascitic fluid infections as culturenegative neutrocytic ascites, monomicrobial nonneutrocytic bacterascites, polymicrobial bacterascites and secondary bacterial peritonitis [5].

The advent of the SBP carries a poor prognosis where the hospital mortality ranged from 10 to $50 \%$. As a consequence, any patient with SBP should be assessed for liver transplantation. Immediate treatment with antibiotics and IV albumin should be initiated [4].

Studies were conducted on alternatives of the ascitic PMN count as high sensitivity C-reactive protein (hsCRP) [6], serum procalcitonin [7], urinary lipocalin [8], ascitic lactoferrin [9], homocysteine [10] and fecal or ascitic calprotectin [11, 12].

This study aimed to assess ascitic calprotectin as a diagnostic marker of SBP. 


\section{Methods}

Patients were recruited from the outpatient clinics of the Internal Medicine Department, Faculty of Medicine for Girls, El Azher University, Department of Hepatology and Gastroenterology, National Liver Institute, Menoufia University and Theodor Bilharz Research Institute, Cairo Egypt. The study was approved by the institutional review board of Faculty of Medicine for Girls, El Azhar University.

This study enrolled 80 patients out of 300 patients with decompensated liver cirrhosis with ascites who were referred for paracentesis, evaluation of abdominal pain or exclusion of ascitic fluid infection in patients with hepatic encephalopathy or gastrointestinal bleeding. Liver cirrhosis was diagnosed according to the characteristic clinical, laboratory, radiological findings that are supported by previous liver biopsy if available and not contraindicated [13].

History taking, full clinical examination, liver function tests, serum creatinine, CBC, INR, serum hsCRP, nitrous oxide, abdominal ultrasonography and ascitic fluid analysis were done on admission.

The ascitic fluid analysis parameters were PMN count, calprotectin, nitrous oxide, total protein, albumin, LDH and glucose and was tested also with leukocyte esterase dipsticks. In the case of SBP diagnosis, inoculation of bedside $10 \mathrm{~mL}$ of ascitic fluid into a blood culture bottle was done [2, 4]. Patients with SBP [8] underwent immediate treatment with $3^{\text {rd }}$ generation cephalosporin and follow up ascitic fluid PMN $48 \mathrm{~h}$ after the start of treatment [4].

\section{Sampling and methodology}

Five $\mathrm{mL}$ blood was withdrawn by venipuncture, one $\mathrm{ml}$ in EDTA tube for $\mathrm{CBC}$ and four $\mathrm{ml}$ were allowed to clot. The non-hemolyzed sera were separated by centrifugation and used for determination of creatinine, uric acid, CRP, (hsCRP), nitric oxide level and liver functions (ALT, AST, total bilirubin and albumin).

The ascitic fluid sample was taken by paracentesis performed under aseptic conditions from a puncture site in the left or right lower quadrant with the patient in the supine position. All samples were immediately collected at the bedside and processed by laboratory personnel without further delay.

Immediately after the paracentesis, the ascitic fluid was tested by the use of reagent strips for the leukocyte esterase designed for rapid urine screening (Mission Expert Urinalysis Reagent Strips, Acon Laboratories, Inc, USA). Fresh ascitic fluid was collected in a clean container and the strip was immediately immersed in the ascitic fluid. We compared closely the test areas with the color chart on the bottle label after $120 \mathrm{~s}$ according to the manufacturer instructions. The strips have a colorimetric 4-grade scale.

Blood glucose, liver profile, and creatinine concentrations were measured on a Dimension Xpand plus chemistry analyzer (Roche Diagnostics, Basel, Switzerland) using commercially available reagents and an enzymebased kit. Complete blood picture was measured using CELL-DYN Emerald cell counter (ABBOTT, Germany). CRP and hsCRP were measured using BIOS microwell ELISA Diagnostic Systems Kit, South San Francisco. Ascitic fluid nitric oxide level was measured using Griess Reagent Nitrite Measurement Kit, Cell Signaling Technology, USA. Ascitic fluid calprotectin was measured by using Human Calprotectin (CALPRO) ELISA kit, Assay Kit Co, USA

\section{Statistical analysis}

Data were statistically analyzed using $\mathrm{IBM}^{\bullet} \mathrm{SPSS}^{\bullet}$ Statistics $^{\ominus}$ version 21 for Windows (IBM Corporation, North Castle Drive, Armonk, New York, USA) and MedCalc ${ }^{\circ}$ version 18.2.1 (Seoul, Republic of Korea). Data are expressed as mean \pm standard deviation for normally distributed data, median (interquartile range) for data that lacks normal distribution and number (percentage) for nominal data. Comparisons between two groups were performed using the Student's $t$ test for parametric data and Mann-Whitney test for non-parametric data. CHI-squared test $\left(x^{2}\right)$ and Fisher exact test for categorical data analysis. Univariate and multivariate binary logistic regression was done for detecting the independent predictors of SBP. The receiver operating characteristic (ROC) curve analysis was used for the detection of the cutoff value of the calprotectin in the diagnosis of SBP.

\section{Results}

This study enrolled 80 patients with ascites that were divided into 2 equal groups; with and without SBP.

The average age of our patients was 55.25 \pm 7.89 years, mostly males ( $n=51,63.8 \%)$, anti-HCV antibodies were positive in $76.3 \%$ of the patients. Sixtyfour patients (80\%) were Child-Pugh $\mathrm{C}$ and their average MELD was $24.29 \pm 8.06$.

Both groups had comparable age, sex, viral etiology of liver disease, serum AST, serum ALT, creatinine and blood hemoglobin (Table 1).

Patients with SBP had statistically significant higher median total bilirubin ( 4.2 vs. $2.3 \mathrm{mg} / \mathrm{dL})$, WBCs $(9800$ vs. $4150 \mu \mathrm{L}$ ), INR (3.4 vs. 1.9), MELD score (26.5 vs. 19), and average CTP score $(12.18 \pm 1.74$ vs. $10.5 \pm 1.97)$. Both serum albumin and platelets were statistically lower in patients with SBP.

Both the serum and ascitic nitrous oxide did not differ statistically between patient with and without SBP. In contrast, patients with SBP had higher median serum 
Table 1 Comparison of patients with and without SBP

\begin{tabular}{|c|c|c|c|c|}
\hline & None & SBP & $P$ & \\
\hline & $n=40$ & $n=40$ & & \\
\hline Age (years) & $54.75 \pm 8.19$ & $55.75 \pm 7.64$ & 0.574 & NS \\
\hline Males & $25(62.5 \%)$ & $26(65 \%)$ & 0.816 & NS \\
\hline Females & $15(37.5 \%)$ & $14(35 \%)$ & & \\
\hline $\mathrm{HCV}$ & $30(75 \%)$ & $31(77.5 \%)$ & 0.793 & NS \\
\hline HBV & $10(25 \%)$ & $9(22.5 \%)$ & & \\
\hline CTP B & $12(30 \%)$ & $4(10 \%)$ & 0.025 & S \\
\hline CTP C & $28(70 \%)$ & $36(90 \%)$ & & \\
\hline Total bilirubin (mg/dL) & $2.3(1.28)$ & $4.2(4.9)$ & 0.001 & S \\
\hline Albumin (mg/dL) & $2.25(1.1)$ & $1.8(0.8)$ & 0.006 & $S$ \\
\hline AST (U/L) & $77.50(28)$ & $73(17.25)$ & 0.083 & NS \\
\hline ALT (U/L) & $46.00(26.25)$ & $43(21.25)$ & 0.146 & NS \\
\hline Hemoglobin (g/dL) & $10.10 \pm 1.71$ & $10.11 \pm 1.14$ & 0.969 & NS \\
\hline WBCs $(\mu \mathrm{L})$ & $4150(5475)$ & $9800(4375)$ & 0.001 & $S$ \\
\hline Platelets ( $\mu \mathrm{L}$ ) & $89,000(22,250)$ & $82,500(32,750)$ & 0.008 & S \\
\hline INR & $1.9(0.7)$ & $3.4(1.45)$ & 0.001 & $S$ \\
\hline Creatinine (mg/dL) & $1.1(0.85)$ & $1.65(1.4)$ & 0.274 & NS \\
\hline CTP & $10.5 \pm 1.97$ & $12.18 \pm 1.74$ & 0.001 & $S$ \\
\hline MELD & $19(8)$ & $26.5(11)$ & 0.001 & S \\
\hline Ascitic PMN & $65(76.75)$ & $657.5(652)$ & 0.001 & S \\
\hline Ascitic total protein & $0.41(0.85)$ & $0.8(0.75)$ & 0.004 & $S$ \\
\hline Ascitic albumin & $0.11(0.35)$ & $0.22(0.38)$ & 0.025 & S \\
\hline Ascitic glucose & $126(110)$ & $125.5(116.75)$ & 0.769 & NS \\
\hline Ascitic LDH & $20.65(26.65)$ & $101(198.25)$ & 0.001 & $S$ \\
\hline Serum NO $(\mu M)$ & $15.5(8.78)$ & $17(12.2)$ & 0.357 & NS \\
\hline Ascitic NO $(\mu \mathrm{M})$ & $5.6(6.4)$ & $6.2(4.5)$ & 0.739 & NS \\
\hline Serum CRP (mg/dL) & $12(11.5)$ & $49(66.25)$ & 0.001 & $S$ \\
\hline Serum hsCRP (ng/dL) & $23,750(52,200)$ & $58,000(0)$ & 0.001 & S \\
\hline Ascitic calprotectin (ng/mL) & $1.1(0.6)$ & $7.57(6.76)$ & 0.001 & S \\
\hline Ascitic leucocyte esterase +ve & $1(2.5 \%)$ & $38(95 \%)$ & 0.001 & $\mathrm{~s}$ \\
\hline
\end{tabular}

CRP ( 49 vs. $12 \mathrm{mg} / \mathrm{dL}$ ), hsCRP (58,000 vs. 23,750 ng/dL) and ascitic calprotectin (7.57 vs. $1.1 \mathrm{ng} / \mathrm{mL}$ ). The ascitic leucocyte esterase test was positive in 95\% of SBP patients in contrast to $2.5 \%$ patients without SBP.

As shown in Table 2 and Fig. 1, ascitic calprotectin $>2$ $\mathrm{ng} / \mathrm{mL}$ had $90 \%$ sensitivity, $92.5 \%$ specificity, $92.3 \%$ positive predictive value and $90.2 \%$ negative predictive value (AUC 0.963, 95\% C.I 0.895-0.992, $P=0.001$ ).

By univariate analysis, the independent predictors of SBP (Table 3) were MELD (odds = 1.2), serum CRP (odds $=1.1$ ), serum hsCRP (odds $=1$ ) and ascitic calprotectin (odds $=7.4$ ). On multivariate analysis, only ascitic
Table 2 The receiver operating characteristic (ROC) curve analysis of ascitic calprotectin

\begin{tabular}{ll}
\hline & PCT \\
\hline AUC & 0.963 \\
$P$ & 0.001 \\
$95 \%$ C.I & $0.895-0.992$ \\
Cutoff & $>2$ \\
Sensitivity & $90 \%$ \\
Specificity & $92.5 \%$ \\
PPV & $92.3 \%$ \\
NPV & $90.2 \%$ \\
\hline
\end{tabular}




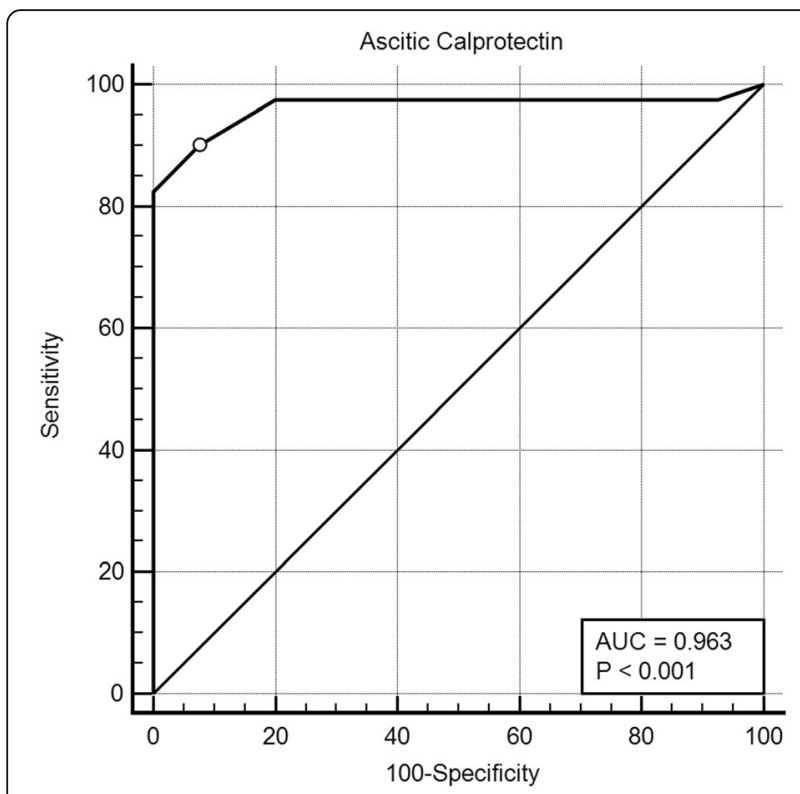

Fig. 1 The receiver operating characteristic (ROC) curve analysis of ascitic calprotectin

calprotectin (odds $=13.1)$ was the independent predictor of SBP.

\section{Discussion}

The gold standard test for SBP is ascitic fluid analysis with measurement of the PMN. It is useful for the diagnosis and monitoring of treatment. The culture of the ascitic fluid may be positive if was done correctly [4].

There is a variant of SBP that is called culture-negative neutrocytic ascites. It is characterized by elevated ascitic fluid PMN but the culture is negative. It is managed exactly as classic SBP. Such cases would be missed if cultures were not done [5].

The manual PMN counting is time consuming, laborious and required some experience to avoid intra- and inter-observer variability. So, a simple rapid bedside test would be useful clinically [14].

Calprotectin is acute-phase inflammatory protein that is released from the PMN. Calprotectin has anti-proliferative and antimicrobial properties [14]. Calprotectin is used clinically widespread in the diagnosis and monitoring treatment of inflammatory bowel disease [15].

In an earlier study [11], patients with liver cirrhosis had higher fecal calprotectin compared with the control. Fecal calprotectin correlated with hepatic encephalopathy grade and SBP.

Later on, studies were conducted on ascitic calprotectin $[12,14,16-18]$. Ascitic calprotectin could be measured by either enzyme-linked immunosorbent assay (ELISA) or a point-of-care (POC) lateral flow assay with the Quantum Blue ${ }^{\circ}$ Reader [16].

Burri et al. [16] reported that patients with SBP had statistically higher values of ascitic calprotectin that was measured by two techniques namely ELISA and POC. A cutoff value $(0.63 \mu \mathrm{g} / \mathrm{mL})$ measured by ELISA had $94.8 \%$ sensitivity, 89.2\% specificity, 60\% PPV and 99\% NPV. A cutoff value $(0.51 \mu \mathrm{g} / \mathrm{mL})$ measured by PCO had $100 \%$ sensitivity, $84.7 \%$ specificity, 100\% PPV and $87.7 \%$ NPV. Both techniques were useful with excellent correlation.

Two studies assessed the ratio of ascitic calprotectin to ascitic total protein. One study [17] found that ratio was useful for SBP diagnosis unlike the other one [12].

Fernandes et al. [12] studied 88 patients of whom 41 had SBP. They were mainly males and alcoholics. Higher ascitic calprotectin was found. A cutoff value $(1.57 \mu \mathrm{g} /$ $\mathrm{mL}$ ) measured by POC had $87.8 \%$ sensitivity, $97.9 \%$ specificity, 97.3\% PPV and 90.2\% NPV.

In the study conducted by Abdel-Razik et al. [18], patients with SBP had higher calprotectin, serum procalcitonin, serum and ascites TNF- $\alpha$, IL- 6 . A cutoff value of $94 \mathrm{ng} / \mathrm{mL}$ had $94.3 \%$ sensitivity, $91.8 \%$ specificity, $93 \%$ PPV and 95\% NPV.

In a recent French study [14], a $1.51 \mu \mathrm{g} / \mathrm{mL}$ cutoff measured by POC had $86.1 \%$ sensitivity, $92 \%$ specificity, 65.9\% PPV and 97.3\% NPV.

CRP is acute-phase protein that elevates in many inflammatory conditions. The hsCRP measures the low levels of CRP. The hsCRP has a higher sensitivity than CRP. Patients with SBP show elevated CRP levels that decrease with treatment $[12,14,19]$. Only one study by Guler et al. [6] assessed the role of serum hsCRP in nonneutrocytic ascites. They found that hsCRP was higher in patients with SBP and non-neutrocytic ascites

Table 3 Independent predictors of SBP

\begin{tabular}{|c|c|c|c|c|c|c|}
\hline & \multicolumn{3}{|c|}{ Univariate analysis } & \multicolumn{3}{|c|}{ Multivariate analysis } \\
\hline & Odds & $P$ & 95\% C.I. & Odds & P & 95\% C.I. \\
\hline Age & 1.0 & 0.569 & $0.961-1.075$ & 0.9 & 0.285 & $0.701-1.110$ \\
\hline MELD & 1.2 & 0.001 & $1.103-1.319$ & 1.1 & 0.438 & $0.843-1.486$ \\
\hline Ascitic calprotectin & 7.4 & 0.001 & $2.420-22.855$ & 13.1 & 0.009 & $1.886-90.405$ \\
\hline Serum CRP & 1.1 & 0.001 & $1.038-1.105$ & 1.1 & 0.101 & $0.986-1.171$ \\
\hline Serum hsCRP & 1.0 & 0.001 & $1.000-1.000$ & 1.0 & 0.979 & $1.000-1.000$ \\
\hline
\end{tabular}

MELD Model for End-Stage Liver Disease, CRP C-reactive protein, hsCRP High sensitivity C-reactive protein 
compared with the control. The levels decreased with antibiotic therapy. Leukocyte esterase is an enzyme produced by PMN in response to inflammation. It can be detected by leucocyte esterase reagent strips.

In the current study, the measurement of serum or ascitic nitrous oxide did not add a benefit in SBP diagnosis. Patients with SBP had higher serum CRP level, which is consistent with the other studies [12, 14, 19]. Furthermore, serum hsCRP was higher in SBP patients in accord with Guler et al. [6] study. Most patients had positive ascitic leucocyte esterase test (95\%) in contrast few patients in the control group.

Calprotectin was significantly higher in SBP patients. Calprotectin $>2 \mathrm{ng} / \mathrm{mL}$ had $90 \%$ sensitivity, $92.5 \%$ specificity, $92.3 \%$ positive predictive value and $90.2 \%$ negative predictive value. The cutoff is completely different from other studies [11, 14, 16, 18] even measured by ELISA but the sensitivity and specificity are high as reported by other studies $[11,14,16,18]$. In fact, the methodology of measurement should be standardized in the next studies.

\section{Limitations of the study}

The number of patients is small, we did not follow the treatment measuring calprotectin and so the recurrence.

\section{Conclusion}

Ascitic calprotectin is a useful marker for spontaneous bacterial peritonitis diagnosis.

\section{Abbreviations \\ CRP: C-reactive protein; CTP: Child-Pugh; hsCRP: High sensitivity C-reactive protein; LDH: Lactate dehydrogenase; MELD: Model for End-Stage Liver Dis- ease; NO: Nitrous oxide; PMN: Polymorphonuclear leucocyte count: ROC: Receiver operating characteristic curve; SBP: Spontaneous bacterial peritonitis}

\section{Acknowledgements}

None

\section{Authors' contributions}

MMS, MAE and AY contributed to data collection. EMA, AA, FAA and EAE contributed to study design. AA and EMA contributed to manuscript writing and final revision. All authors have read and approved the manuscript.

\section{Funding \\ None}

\section{Availability of data and materials}

Not applicable

\section{Ethics approval and consent to participate}

The institutional review board of Faculty of Medicine for Girls, El Azhar University (IRB 258765/2017). Written consent was used.

\section{Consent for publication}

All patients signed an informed written consent before enrollment.

\section{Competing interests}

The authors declare that they have no competing interests.

\section{Author details}

${ }^{1}$ Department of Internal Medicine, Faculty of Medicine for Girls, El Azhar University, Cairo, Egypt. ${ }^{2}$ Department of Hepatology and Gastroenterology, National Liver Institute, Menoufia University, Shebeen El-Kom 32511, Egypt. ${ }^{3}$ Department of Hepatology and Gastroenterology, Theodor Bilharz Research Institute, Cairo, Egypt. ${ }^{4}$ Department of Internal Medicine, Faculty of Medicine, Assiut University, Asyut, Egypt. ${ }^{5}$ Department of Medical Microbiology and Immunology, Faculty of Medicine, Cairo University, Cairo, Egypt.

Received: 4 October 2019 Accepted: 23 January 2020

Published online: 27 February 2020

\section{References}

1. Mohamed A, Atef M, Alsebaey A, Musa Elhabshy M, Salama M (2017) Combined spontaneous bacterial empyema and peritonitis in cirrhotic patients with ascites and hepatic hydrothorax, Arab. J Gastroenterol 18(2): 104-107

2. Xiol X, Castellvi JM, Guardiola J, Sese E, Castellote J, Perello A, Cervantes X, Iborra MJ (1996) Spontaneous bacterial empyema in cirrhotic patients: a prospective study. Hepatology 23(4):719-723

3. Bernardi M (2010) Spontaneous bacterial peritonitis: from pathophysiology to prevention. Intern Emerg Med 5(Suppl 1):S37-S44

4. European Association for the Study of the Liver (2010) EASL clinical practice guidelines on the management of ascites, spontaneous bacterial peritonitis, and hepatorenal syndrome in cirrhosis. J Hepatol 53(3):397-417

5. Marciano S, Diaz JM, Dirchwolf M, Gadano A (2019) Spontaneous bacterial peritonitis in patients with cirrhosis: incidence, outcomes, and treatment strategies. Hepat Med 11:13-22

6. Guler K, Vatansever S, Kayacan SM, Salmayenli N, Akkaya V, Erk O, Palanduz A (2009) High sensitivity C-reactive protein in spontaneous bacterial peritonitis with nonneutrocytic ascites. Hepatogastroenterology 56(90):452-455

7. Wu H, Chen L, Sun Y, Meng C, Hou W (2016) The role of serum procalcitonin and $\mathrm{C}$-reactive protein levels in predicting spontaneous bacterial peritonitis in patients with advanced liver cirrhosis. Pak J Med Sci 32(6):1484-1488

8. Fouad TR, Abdelsameea E, Elsabaawy M, Ashraf Eljaky M, Zaki ElShenawy S, Omar N (2019) Urinary neutrophil gelatinase-associated lipocalin for diagnosis of spontaneous bacterial peritonitis. Trop Doct 49475519830265

9. Parsi MA, Saadeh SN, Zein NN, Davis GL, Lopez R, Boone J, Lepe MR, Guo L, Ashfaq M, Klintmalm G, McCullough AJ (2008) Ascitic fluid lactoferrin for diagnosis of spontaneous bacterial peritonitis. Gastroenterology 135(3):803-807

10. Abdel-Razik A, Eldars W, Elhelaly R, Eldeeb AA, Abdelsalam M, El-Wakeel N, Aboulmagd A (2018) Homocysteine: a new diagnostic marker in spontaneous bacterial peritonitis. Eur J Gastroenterol Hepatol 30(7):779-785

11. Gundling F, Schmidtler F, Hapfelmeier A, Schulte B, Schmidt T, Pehl C, Schepp W, Seidl H (2011) Fecal calprotectin is a useful screening parameter for hepatic encephalopathy and spontaneous bacterial peritonitis in cirrhosis. Liver Int 31(9):1406-1415

12. Fernandes SR, Santos P, Fatela N, Baldaia C, Tato Marinho R, Proença H, Ramalho F, Velosa J (2016) Ascitic calprotectin is a novel and accurate marker for spontaneous bacterial peritonitis. J Clin Lab Anal 30(6):1139-1145

13. Schuppan D, Afdhal NH (2008) Liver cirrhosis. Lancet 371(9615):838-851

14. Weil D, Heurgue-Berlot A, Monnet E, Chassagne S, Cervoni J-P, Feron T, Grandvallet C, Muel E, Bronowicki J-P, Thiefin G, Di Martino V, Bardonnet K, Thévenot T (2019) Accuracy of calprotectin using the Quantum Blue Reader for the diagnosis of spontaneous bacterial peritonitis in liver cirrhosis. Hepatol Res 49(1):72-81

15. Reenaers C, Bossuyt P, Hindryckx P, Vanpoucke H, Cremer A, Baert F (2018) Expert opinion for use of faecal calprotectin in diagnosis and monitoring of inflammatory bowel disease in daily clinical practice. United European Gastroenterol J 6(8):1117-1125

16. Burri E, Schulte F, Muser J, Meier R, Beglinger C (2013) Measurement of calprotectin in ascitic fluid to identify elevated polymorphonuclear cell count. World J Gastroenterol 19(13):2028-2036

17. Lutz P, Pfarr K, Nischalke HD, Kramer B, Goeser F, Glassner A, Wolter F, Kokordelis P, Nattermann J, Sauerbruch T, Hoerauf A, Strassburg CP, Spengler $U$ (2015) The ratio of calprotectin to total protein as a diagnostic 
and prognostic marker for spontaneous bacterial peritonitis in patients with liver cirrhosis and ascites. Clin Chem Lab Med 53(12):2031-2039

18. Abdel-Razik A, Mousa N, Elhammady D, Elhelaly R, Elzehery R, Elbaz S, Eissa M, El-Wakeel N, Eldars W (2016) Ascitic fluid calprotectin and serum procalcitonin as accurate diagnostic markers for spontaneous bacterial peritonitis. Gut Liver 10(4):624-631

19. Metwally K, Fouad T, Assem M, Abdelsameea E, Yousery M (2018) Predictors of spontaneous bacterial peritonitis in patients with cirrhotic ascites. J Clin Transl Hepatol 6(4):372-376

\section{Publisher's Note}

Springer Nature remains neutral with regard to jurisdictional claims in published maps and institutional affiliations.

Submit your manuscript to a SpringerOpen ${ }^{\mathcal{O}}$ journal and benefit from:

- Convenient online submission

Rigorous peer review

- Open access: articles freely available online

High visibility within the field

- Retaining the copyright to your article

Submit your next manuscript at $\boldsymbol{\sim}$ springeropen.com 